\title{
Wonders of Human's Cerebrum via Art
}

\section{Abraham Tamir*}

Department of Chemical Engineering, Ben-Gurion University of the Negev, Beer-Sheva, Israel

The cerebrum, which is just Latin for "brain", is the largest part of the brain as a whole. It is here that things like perception, imagination, thought, judgment, and decision occur. In daily use the word "brain" is more applicable so it will be used in the following. Human's brain is the most important and complex organ in our body, weighing $1.3 \mathrm{~kg}$ and consisting of more than 10 billion nerve cells known as neurons. It is the interaction among these cells, existing also in all our body that makes the brain such a perfect machine and forms the basis for learning and memory processes. It allows us to think, move, feel, see, hear, taste, and smell. It controls our body, receives information, analyzes information, and stores information-our memories. The brain produces electrical signals, which, together with chemical reactions, let the parts of the body communicate whereas nerves send these signals throughout the body. The brain is only $2 \%$ of the body's weight; however it uses $20 \%$ of the oxygen supply and gets $20 \%$ of the blood flow. Blood vessels-arteries, capillaries, and veins-supply the brain with oxygen and nourishment and take away wastes. If brain cells do not get oxygen for 3 to 5 minutes, they begin to die.

Although the two sides of the brain look like mirror images of each other, they are different in their functioning. The right side of your brain controls the left side of your body, and the left hemisphere controls the right side. In most people, the left hemisphere is important for language, mathematics and reasoning as well as giving man science and technology. The right side is more important for emotion, recognizing faces and music and is responsible for art and imagination.

Figures 1(a,b) demonstrate front views of the brain. Figure 1(a) was painted by the American artist Alex Grey (b.1953) specializing in spiritual and visionary art. It is entitled "Visdera" and is an external

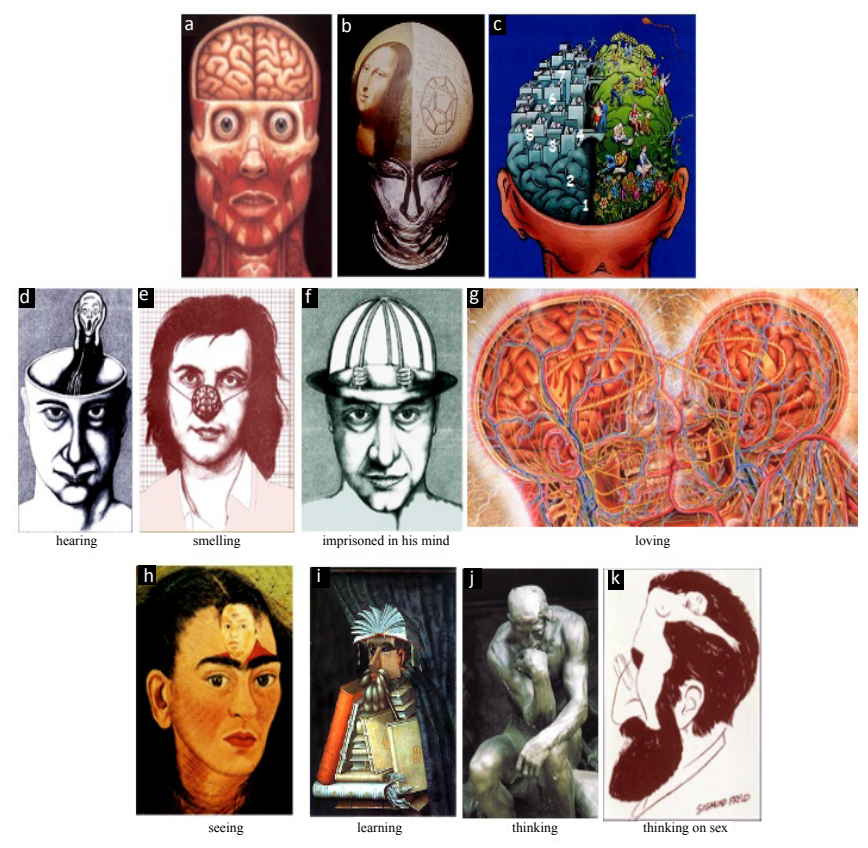

Figure 1: Images related to the article(a-k). view of the brain giving the impression that both halves look like mirror images of each other. On the other hand Figure 1(b) by an unknown artist emphasizes the fact that practically the two halves are not the same, where Figure 1(c) demonstrates artistically the different zones in the brain as follows. 1-visual area where below is located the dreams area only recently identified; 2-lanuage area; 3 -auditory area; 4-sensory area; 5-motor area; 6-premotor area; 7-frontal area. It should be noted that all above areas exist also symmetrically on the right part of the brain.

In the following we demonstrate by artworks a few performances of the brain. The Czech artist Oliver Solga (b.1954) painted Figure 1 (d-f). Figure 1(d) describes the function of "hearing" by inserting into a brain the image of the screamer of the famous artwork "The Scream" by the Norwegian expressionist artist Edvard Munch (1863-1944). The function of "smelling" is presented in an original way by transplanting a section of the brain on the nose where a stubborn person or somebody imprisoned in his mind related absolutely to the performance of the brain is convincingly demonstrated in Figure 1(f). Love is demonstrated in Figure $1(\mathrm{~g})$ painted by Alex Grey. The symbol of infinity that symbolizes infinite love connects the two brains. Frida Kahlo (19071954), one of the most influential Mexican painters of the middle twentieth century, painted Figure 1(h) on purpose to demonstrate the "seeing" functioning of the brain. Her life was involved with that of Diego Rivera, her mentor, husband and largest artistic influence. Frida's love to Diego and thinking about him all the time is demonstrated in Figure 1(h) where the face of Diego is reflected in her brain. Figure 1(i), "The Librarian", was painted by Giuseppe Arcimboldo (1527-1593) who was an Italian painter best known for creating imaginative portrait heads made entirely of such objects as fruits, vegetables, flowers, fish, and books. The location of the books in the painting may be looked upon as demonstrating the action of "learning" executed in the brain. Figure 1(j) is the famous sculpture "The Thinker". Auguste Rodin (18401917), a French artist, most famous as a sculptor constructed it where it demonstrates the action of "thinking" carried out in the brain. And finally, a humorous demonstration of "thinking" is presented in Figure 1(k) painted by Sigmund Freud (1856-1939), an Austrian physician who founded the psychoanalytic school of psychology.

*Corresponding author: Abraham Tamir, Department of Chemical Engineering Ben-Gurion University of the Negev, Beer-Sheva, Israel, E-mail: atamir4@012.net.il

Received April 21, 2014; Accepted April 22, 2014; Published April 30, 2014

Citation: Tamir A (2014) Wonders of Human's Cerebrum via Art. Ind Eng Manage 3: e123. doi: 10.4172/2169-0316.1000e123

Copyright: (c) 2014 Tamir A. This is an open-access article distributed under the terms of the Creative Commons Attribution License, which permits unrestricted use, distribution, and reproduction in any medium, provided the original author and source are credited. 